\title{
My experience with cubital tunnel syndrome
}

\author{
Goo Hyun Baek \\ From 10th Congress of the Asia-Pacific Federation of Societies of Surgery fo the Hand and the 6th Congress \\ of Asia-Pacific Federation of Societies of Hand Therapists \\ Kuala Lumpur, Malaysia. 2-4 October 2014
}

Cubital tunnel syndrome can be defined as a compressive neuropathy of the ulnar nerve around the elbow from the arcade of Struthers to the flexor-pronator aponeurosis. However, this complex neuropathy is related not only with compressive force but also with tensile force caused by elongation of the ulnar nerve while flexing the elbow joint and with friction force caused by excursion of the nerve during elbow motion.

\section{Anatomic considerations}

There are five potential sites for the ulnar nerve compression around the elbow - arcade of Struthers, medial intermuscular septum, cubital tunnel retinaculum (Osborne's ligament), Osborne's fascia covering two heads of flexor carpi ulnaris, and deep flexor-pronator aponueurosis. Sometimes, the ulnar nerve can be compressed by synovial hypertrophy of the elbow in rheumatoid disease, the presence of the tumors such as ganglion or lipoma, or aberrant muscles such as anconeus epitrochlearis.

Bony structure of the cubital tunnel can be easily seen by a simple $\mathrm{X}$-ray, the cubital tunnel view, which is an AP view with full flexion and 20 degrees of external rotation of the elbow. I proposed two parameters of the cubital tunnel view, cubital tunnel angle (CTA) and cubital tunnel depth (CTD) (Figure 1). When the CTA is smaller, the angle is narrower; or when the CTD is large, the depth is deeper than normal, thus the chance of ulnar nerve irritation at the cubital tunnel will be increased.

The bony anatomy of the cubital tunnel is one of the important etiologic factors in cubital tunnel syndrome, as well as abnormalities of soft tissue anatomy.

\section{Operative procedures}

Initial conservative therapy is widely recommended for mild cases of cubital tunnel syndrome, however, there

$$
\text { Department of Orthopaedic Surgery, Seoul National University Hospital, }
$$$$
\text { Seoul, 110-744, Korea }
$$

have been no general agreement on the indications and specific methods of surgery for the more severe cases.

Although there are many operative procedures described for the treatment of cubital tunnel syndrome, these can be categorized into three groups - in situ decompression (open or endoscopic), decompression and anterior transposition (subcutaneous or submuscular), and in situ decompression and medial epicondylectomy.

I prefer in situ decompression when cubital tunnel angle (CTA) and cubital tunnel depth (CTD) are within normal limits. However, when the CTA is narrower and/or CTD is deeper than normal I do minimal medial epicondylectomy as well as in situ decompression.

The main advantage of this technique (in situ decompression + minimal medial epicondylectomy) is to broaden CTA and shorten CTD (Figure). Other advantages of this procedure include preservation of the ulnar nerve blood supply, minimizing trauma to the nerve, smaller incision than anterior transposition technique, and nerve decompression posterior to the medial epicondyle. Although some disadvantages such as loss of the protective prominence of the medial epicondyle, postoperative tenderness at the osteotomy site, and weakness related to detachment of the flexor pronator origin, these complications are very rare in my hand.

\section{Summary}

A good deal of controversy surrounds the natural history, pathogenesis, surgical indications, and methods of surgery for cubital tunnel syndrome. The surgical treatment options for the ulnar nerve entrapment at the elbow include in situ decompression (open or endoscopic), decompression and anterior transposition (subcutaneous or submuscular), and in situ decompression and medial epicondylectomy, all of which are used with relative frequency based on surgeon preference. Considering the importance of bony anatomy of the cubital tunnel such as CTA and CTD, minimal medial epicondylectomy is 


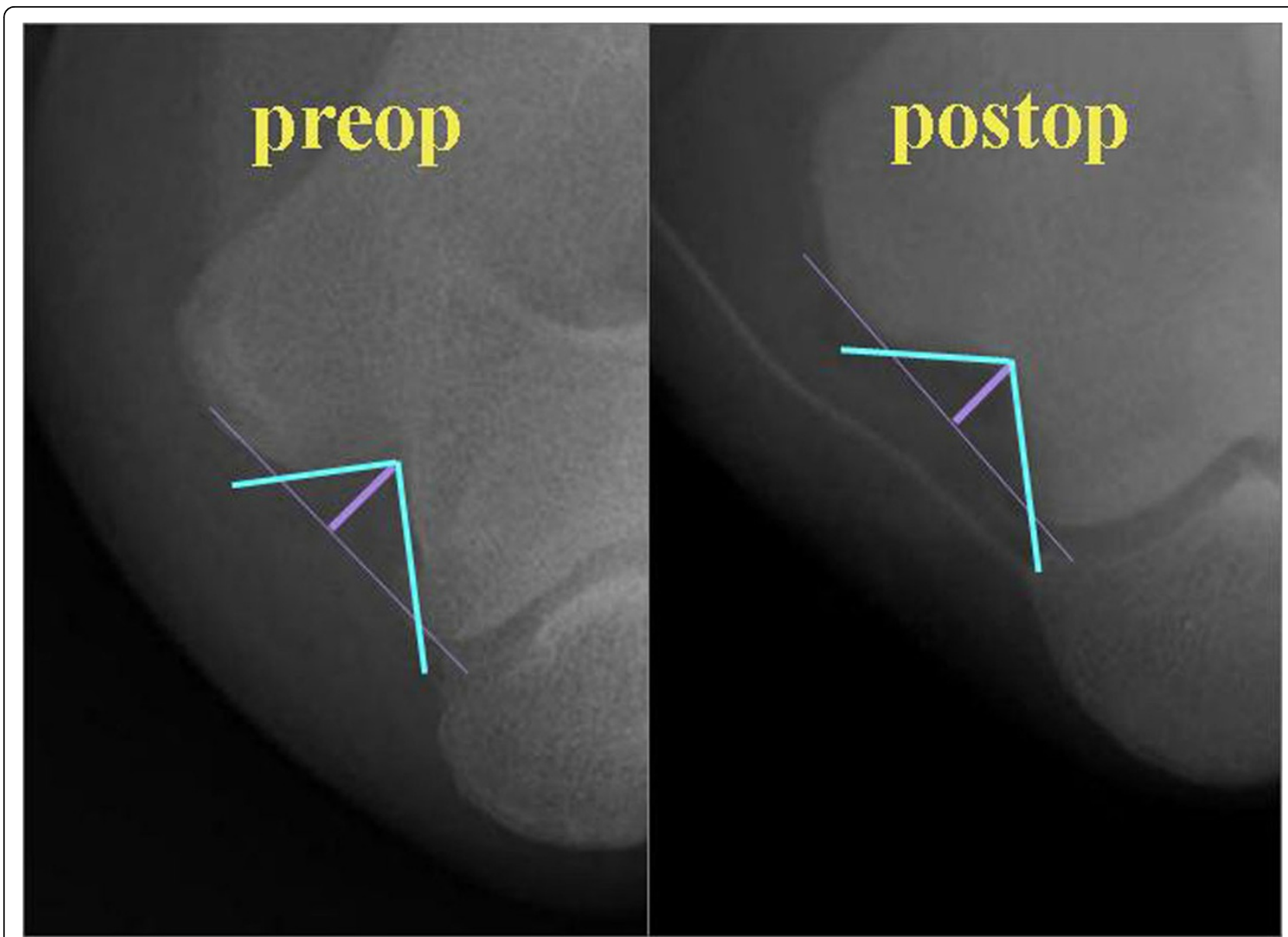

Figure 1 Both cubital tunnel angle (CTA) and cubital tunnel depth (CTD) became wider and shallower after minimal medial epicondylectomy and in situ decompression

necessary to be combined with in situ decompression especially when CTA is narrow and/or CTD is deep.

Published: 19 May 2015

\section{References}

1. Baek GH, Kwon BC, Chung MS: Comparative study between minimal medial epicondylectomy and anterior subcutaneous transposition of the ulnar nerve for cubital tunnel syndrome. J Shoulder Elbow Surg 2006, 15(5):609-613.

2. Kim KW, Lee HJ, Rhee SH, Baek GH: Minimal epicondylectomy improves neurologic deficits in moderate to severe cubital tunnel syndrome. Clin Orthop Relat Res 2012, 470(5):1405-1413.

doi:10.1186/1753-6561-9-S3-A75

Cite this article as: Baek: My experience with cubital tunnel syndrome. BMC Proceedings 2015 9(Suppl 3):A75.

\section{Submit your next manuscript to BioMed Central} and take full advantage of:

- Convenient online submission

- Thorough peer review

- No space constraints or color figure charges

- Immediate publication on acceptance

- Inclusion in PubMed, CAS, Scopus and Google Scholar

- Research which is freely available for redistribution

Submit your manuscript at www.biomedcentral.com/submit 